\title{
The Evolution of Natural Fats
}

\section{A General Survey}

\author{
By Prof. T. P. Hilditch and Dr. J. A. Lovern
}

$\mathrm{M}^{\mathrm{s}}$ ETABOLIC processes and products in living organisms are frequently specific, and it is interesting to consider what relation a classification of organisms according to their characteristic chemical products would bear to that based upon morphology. In a number of cases it has already been realised that chemical peculiarities in plants or animals are specific for a number of biologically related organisms and for no other species. The generalisations of Baker and Smith on the types of essential oils produced in different groups of eucalypts are a case in point. Similarly, it has been realised for some time that in the seed-fats of some plant families specific fatty acids are elaborated in quantity (for example, lauric in the Palmæ, myristic in Myristicaceæ, erucic in Brassica, etc.) ; while the recent observations of Heilbron and co-workers on the pigments and sterols of certain algæ disclose similar specific relationships.

Hitherto sufficient differentiation has not been defined, in any one group of related chemical compounds common to practically all organisms, to permit a comprehensive view of all forms of living matter from the metabolic or chemical standpoint. Of recent years, however, a very wide range of natural fats (triglycerides) has received detailed attention and, although there are still many lacunæ in the available data, it has become increasingly evident that many close parallelisms exist between the kind and proportions of fatty acids combined as triglycerides in living plant or animal organisms, their classification on morpho. logical grounds, and their places in the evolutionary scale of development.

Of all the constituents of living organisms, the fats (triglycerides) are exceptionally suited to such comparisons because they contain in combination a number, often a considerable number, of individual acids which can be both qualitatively and, at least approximately, quantitatively determined. There is also considerable variation in the par. ticular acids present, or in their proportions, in organisms of different types. These acids may be saturated (lauric, palmitic, stearic, etc.) or unsaturated (oleic, linoleic, erucic, etc.), and in the latter group the unsaturation may be restricted to one ethylenic union or may extend to as many as four, five or six. Taking the theory of evolution as a general background (as in biological correlations based upon morphology or anatomy), some interesting relationships become apparent when we review progressive differences in fat types. From this point of view we commence with the fats of aquatic life, in the light of recent studies at the Torry Research Station.

All fats of aquatic origin are characterised by the presence in combination with glycerol of an exceptional variety of acids, mainly of the un. saturated series. The saturated acids usually form only 15-20 per cent of the whole, and of these palmitic acid, $\mathrm{C}_{16} \mathrm{H}_{32} \mathrm{O}_{2}$, is the chief, the others (myristic and stearic) often only amounting to about 2-4 per cent and 1-2 per cent respectively of the total fatty acids. The unsaturated acids include, on the other hand, members containing $16,18,20,22$ and even 24 carbon atoms in the molecule (conveniently referred to as glycerides of unsaturated $\mathrm{C}_{16}{ }^{-}, \mathrm{C}_{18}^{-}, \mathrm{C}_{20}{ }^{-}, \mathrm{C}_{22}^{-}, \mathrm{C}_{21}^{-}$acids) in varying proportions and degrees of unsaturation. In fats from all freshwater life, plant or animal, small or large, the type appears to be much the same, namely, that containing relatively high proportions of unsaturated acids of the $\mathrm{C}_{18}{ }^{-}$and $\mathrm{C}_{16}{ }^{-}$series, with low contents of those of the $\mathrm{C}_{20}{ }^{-}$and $\mathrm{C}_{22}{ }^{-}$series (the latter often being minimal). Again, both freshwater and marine algæ of the Chlorophyceæ have the same type of fat, and it appears that here both for fat type and morphology salinity has made no real difference. In the more specialised brown and red marine algæ the fat type is definitely altered, the component acids still being aquatic in range but with quantitative differences in the relative proportions of the various homologous unsaturated members. The diatoms resemble the green algæ alike in that many species can live in either fresh or salt water and that their fat is of the 'freshwater' type in all instances so far studied.

We pass on to a more general survey of aquatic animal fats. Throughout the whole animal life of fresh water we find one broad type of fat onlythat already referred to as characteristic of freshwater flora. In other words, for the whole of fresh. water life the relative proportions of the com. ponent acids are of the same order throughout (at the same time minor differences are to be observed, for example, higher degrees of unsatura. tion in the acids, and concurrent presence of small proportions of higher alcohols as well as glycerol, in the plankton Crustacea in contrast to 
fishes, etc.). In the marine world, on the other hand, salinity or some other factor has led to a definite alteration in fat type. While, as has been said, marine diatom fat (so far as at present studied) is similar to the 'freshwater' type, the fat of marine plankton Crustacea (which feed on the diatoms) is considerably different in composition-unsaturated $\mathrm{C}_{16}{ }^{-}$and $\mathrm{C}_{18}{ }^{-}$acids are reduced in amount and $\mathrm{C}_{20} 0^{-}$, and especially $\mathrm{C}_{22}{ }^{-}$, acids are correspondingly increased. This crustacean fat type persists as a general background throughout almost the whole range of marine fish and mammalia, although it may again be modified in certain families in various ways. In elasmobranch fish, for example, the triglycerides are often accompanied by abnormal proportions of non-fatty compounds, including especially the hydrocarbon squalene and sometimes the glycerol ether-esters known as batyl, etc., alcohols; when these substances are also produced in quantity it has invariably been found that the unsaturation of the acids in the triglycerides is almost wholly monoethenoid.

Similar specific features include the elaboration of esters of higher alcohols as well as triglycerides in depot fats of the Physeteridx (here, again, the unsaturation of the acids present is abnormally low), and that of mixed glycerides of the quite exceptional isovaleric acid in those of the Delphinidæ; such differences are as definitely characteristic as those in the anatomical features of the respective groups. Other interesting marine animal fats include those of the sturgeon, which are of the freshwater type; while salmon body fats alter progressively as the fish develop from purely freshwater to marine animals.

As we pass from depot fats of aquatic to those of land animals we find marked simplification in the mixed fatty acids, and in the higher land animals the important component acids are almost always the (monoethenoid) oleic, $\mathrm{C}_{18} \mathrm{H}_{34} \mathrm{O}_{2}$, and the (saturated) palmitic, $\mathrm{C}_{16} \mathrm{H}_{32} \mathrm{O}_{2}$, the latter occurring in much larger proportions than in aquatic animal fats, namely, about 25-30 per cent of the total fatty acids-a figure which is roughly the same for the depot fats of widely different animals such as the rat, rabbit, pig, sheep, ox, reindeer, horse and also, apparently, birds. Nevertheless, the disappearance of the characteristic 'aquatic' unsaturated acids of the $\mathrm{C}_{10}{ }^{-}$ (mainly monoethenoid, palmitoleic), $\mathrm{C}_{18}{ }^{-}, \mathrm{C}_{20}{ }^{-}$and $\mathrm{C}_{22}-$ (mono- and poly-ethenoid) series is by no means abrupt. Klenk has established the interesting fact that, in depot fats of amphibians and reptiles, unsaturated $\mathrm{C}_{10^{-}}, \mathrm{C}_{20^{-}}$and $\mathrm{C}_{22}{ }^{-}$acids are present, but in less amount than in fish depot fats: frog depot fat contained 15 per cent of palmitoleic and the same amount of unsaturated $\mathrm{C}_{20-22}$-acids, that of the lizard, 10 per cent of the $\mathrm{C}_{18^{-}}$, and 5 per cent of the $\mathrm{C}_{20-22}-$ acids, while in the depot fat of the Greek tortoise the respective proportions were 9 and 7 per cent. The unsaturation of the $\mathrm{C}_{20-22}$-acids, though still high, was not so pronounced as in the fish oils. In these fats the proportion of saturated acids was not very different from that in 'aquatic' fats, and the drop in unsaturated $\mathrm{C}_{16^{-}}, \mathrm{C}_{20}{ }^{-}$and $\mathrm{C}_{22}{ }^{-}$acids is balanced chiefly by increase in unsaturated $\mathrm{C}_{18}{ }^{-}$ (mainly oleic) acid. Work at Liverpool had previously shown the presence of small quantities (6-8 per cent) of palmitoleic acid in the depot fats of rats and of the domestic fowl, together with minor amounts $(0 \cdot 5-1$ per cent) of unsaturated $\mathrm{C}_{20}-$ and $\mathrm{C}_{22}-$ acids. The latter acids were already known, from the work of J. B. Brown and his colleagues, to be present in very small proportions in other animal depot fats (for example, pig) and in cow milk fat. In rats, rabbits and hens, in contrast to the frog, lizard and tortoise, the saturated acids of the depot fats form 30-35 per cent of the total acids (palmitic, 25-28 per cent).

Klenk has considered the connexion between body temperature and the amounts and degree of unsaturation of the $\mathrm{C}_{20^{-}}$and $\mathrm{C}_{22}{ }^{-}$acids; we would point out here the progressive changes in depot fat component acids in conjunction with the position of the animals in the evolutionary scale. Perhaps the data we have quoted will be more clear if we tabulate the general range of values so far observed for the main component acids in some of the different groups of the larger animals :

\begin{tabular}{|c|c|c|c|c|c|}
\hline \multirow[t]{2}{*}{ Compon } & \multirow{2}{*}{$\begin{array}{l}\text { Acids (Pe } \\
\text { Saturated } \\
\text { Palmitic }\end{array}$} & \multicolumn{4}{|c|}{ Unsaturated } \\
\hline & & $\begin{array}{c}\mathrm{C}_{18} \\
\text { (Palmitoleic) }\end{array}$ & $\mathrm{C}_{18^{*}}$ & $\mathrm{C}_{20^{-}}$ & $\mathrm{C}_{22}$ \\
\hline $\begin{array}{l}\text { Fish, freshwater } \\
\text { marine } \\
\text { Whales }\end{array}$ & $\begin{array}{l}13-15 \\
12-15 \\
12-15\end{array}$ & $\begin{array}{r}\text { c. } 20 \\
15-18 \\
15-18\end{array}$ & $\begin{array}{l}40-45 \\
27-30 \\
35-40\end{array}$ & $\begin{array}{r}c .12 \\
20-25 \\
15-20\end{array}$ & $\begin{array}{l}0-5 \\
8-12 \\
5-10\end{array}$ \\
\hline $\begin{array}{l}\text { Frog } \\
\text { Tortoise } \\
\text { Lizard } \\
\text { Domestic fowl } \\
\text { Rat } \\
\text { Pig } \\
\text { Ox }\end{array}$ & $\begin{array}{c}11 \\
14 \\
18 \\
25-26 \\
24-28 \\
25-29 \\
27-30\end{array}$ & $\begin{array}{c}15 \\
9 \\
10 \\
6-7 \\
7-8 \\
\text { absent } \\
\text { absent }\end{array}$ & $\begin{array}{c}52 \\
65 \\
56 \\
\text { ca. } 60 \\
\text { ca. } 60 \\
50-65 \\
40-50\end{array}$ & $\begin{array}{r}0.5 \\
0 \cdot 3 \\
0 \cdot 3 \\
\text { abse }\end{array}$ & 5 \\
\hline
\end{tabular}

Almost all the acids other than palmitic (that is, about 70 per cent of the component fatty acids) in the depot fats of the land animals belong to the $\mathrm{C}_{18}$ series. In many cases, apparently (detailed analyses are, curiously, still somewhat scanty in this group except for a few common animals), these acids are largely unsaturated (oleic, with sometimes polyethenoid acids); but in the Ungulata, at all events, stearic glycerides occur, often to a marked degree, in place of oleic glycerides; and specific characteristics in the constitution of the mixed triglycerides in these depot fats, which place them apart from most other natural fats, suggest that the stearic compounds 
are the result of hydrogenation of oleic derivatives. The milk fats of this group, which are, of course, also differentiated by the presence of a certain quantity of lower saturated acids $\left(\mathrm{C}_{4}\right.$ to $\left.\mathrm{C}_{10}\right)$, share with the depot fats this particular type of glyceride structure; this feature has been the subject of many studies in our Liverpool laboratory. In contrast to elaboration of specific lower saturated acids in the milk fat of the larger land mammals, we may note in passing the observation of Schmidt-Nielsen and Frog that the component acids of whale milk fat are almost quantitatively the same as those of its depot (blubber) fat.

In the depot fats of the land animals, there occurs frequently (usually in not very large amounts) the linoleic acid, $\mathrm{C}_{18} \mathrm{H}_{32} \mathrm{O}_{2}$, which is a component of many seed fats ; but there is much reason for thinking that this is derived by assimilation from the latter. At this point it should perhaps also be said that the data quoted above refer to animals which have received their natural diet; it is well known, of course, that higher animals, at all events, are able to ingest fats from vegetable seeds, etc., and to lay down some of the specific acids of the latter in their depot fats, but this aspect of fat deposition has been excluded, so far as possible, in the observations on which this survey is based.

The parallelisms to be observed between fat types and evolution in the animal world, as outlined above, appear to possess a certain significance. It remains now to consider the corresponding sequence in the vegetable kingdom. Here, as in the fauna, the data are most abundant for depot (seed) fats of the more developed land plants; there is at present a great lack of detailed information on the characteristic fats of the lower forms of land flora and also on the glycerides present in the growing parts of the larger plants. Nevertheless, it is interesting that the unsaturated palmitoleic $\left(\mathrm{C}_{10^{-}}\right)$acid, so characteristic of aquatic and lower land animal life, has been observed in quantity in the fats of a bacillus (diphtheria), of yeast (Saccharomyces cerevisice), and of the spores of a cryptogam (Lycopodium), respectively by Chargaff, by Newman and Anderson, and by Riebsomer and Johnson.

There is some evidence that higher aquatic plants, including sub-aquatic grasses, have fat closely resembling freshwater algæ, while the work of Chibnall and others on the glycerides of forage grasses suggests the presence of unsaturated $\mathrm{C}_{18^{-}}$ acids which are not identical with those typical of most seed fats. The component acids of the glycerides of the seeds (and, when present, of the pericarp or other fruit coat) of members of many plant families have, on the other hand, been widely studied in detail in recent years; especially, perhaps, at Liverpool. The first thing which is apparent, in contrast to fats of aquatic flora, is considerable simplification in the component fatty acids. As in the land animals, palmitic and oleic become the most consistently prominent features; but a third acid, linoleic, must be added to these as a component which is of most frequent occurrence. The latter acid is either absent, or only present in small quantities, in most fats of aquatic origin, but it, and the related still more unsaturated linolenic acid, are amongst the most familiar constituents of the widely distributed class of 'drying' seed oils.

Fruit coat fats so far examined include (with at present only one exception) palmitic and oleic acids as sole major components, irrespective of the plant family in which they occur; linoleic acid is also frequently present, but usually only in minor quantities. In many seed fats, also, the bulk of the component acids is palmitic, oleic and linoleic in varying proportions; and, in general, seed fats of the same family have a certain resemblance in the relative proportions of these component acids. Malvaceæ and Bombacaceæ seed-fats, for example, are usually high in their content of palmitic acid (20-25 per cent) and also contain about 50 per cent of linoleic acid. The latter acid is prominent in many seed-fats of the conifers, of the larger dicotyledonous trees and shrubs, and in Rosacex, Compositæ, Labiatæ, Linaceæ and other families, and also in those of Graminex, the component acids of most of which include about 10-15 per cent of palmitic, 30-60 per cent of oleic and $60-30$ per cent of linoleic.

Land plants differ, however, from all other natural sources of fats in that, in many other families, their seed fats include as major compo. nents a fatty acid (or acids) different from any of those previously mentioned; in such cases the occurrence of the specific acid is almost wholly confined to one, or at the most to only a few, of the natural plant families. Thus the unsaturated erucic acid, $\mathrm{C}_{22} \mathrm{H}_{42} \mathrm{O}_{2}$, is present in quantity in all Cruciferous seed fats; a structural isomeride of oleic acid, 'petroselinic acid', is similarly found in seeds of the Umbelliferæ and the closely related ivy; and the cyclic unsaturated chaulmoogric and hydnocarpic acids in some of the Flacourtiacex. of saturated acids, arachidic $\left(\mathrm{C}_{20}\right)$ and ligneceric $\left(\mathrm{C}_{24}\right)$, which occur in minute amounts in many seed fats, only attain major proportions in members of the Sapindacer and some of the Leguminosæ, whilst stearic acid (by no means so common a major component of fats as is usually supposed) is present in quantity only in the seed fats of a few tropical families. Saturated acids of lower molecular weight (lauric, $\mathrm{C}_{12}$, myristic, $\mathrm{C}_{14}$ ) are similarly characteristic of other, mainly tropical, 
families; the composition of all Palmæ seed fats yet studied is remarkable for close quantitative similarity, with lauric (45-48 per cent) and myristic (16-20 per cent) as main components.

Ivanow and others have pointed to climatic temperature as the factor mainly operative in determining the relative saturation of seed fats. Production, in plants of cooler latitudes, of fats solid at the prevailing temperatures of the atmosphere is in any case not very probable; but this is not evidence that the tropical temperature per se causes or favours development of the more saturated fats. Actually, many of the most unsaturated fats (those of Aleurites, Hevea, Perilla, Licania species, to quote only a few) are synthesised in the fruits of plants which can only live in tropical or subtropical conditions. On the other hand, in those plants which thrive both in either hot or cold climates, the investigators quoted have demonstrated a greater production of the char. acteristic unsaturated acids in seeds from plants grown in the cooler regions.

In a few cases, as in Ricinus communis, Picramnia sp. or Aleurites montana and Fordii, the seed fats of one or two species of a genus elaborate quite distinct fatty acids-in the cases mentioned, respectively, ricinoleic (hydroxy-oleic), tariric (acetylenic) and elaeostearic (conjugated triethenoid). The last-named is at present quite exceptional, since it is quite an unusual plant fatty acid, and has yet been observed (in each case in isolated species only) in the three distinct families Euphorbiaceæ, Rosaceæ and Cucurbitaceæ.

Although the biosynthesis of these specific fatty components places many of the higher land plant families apart from the rest of Nature as regards their fat types, we are left with the circumstance that the occurrence of these unusual features runs on the whole remarkably parallel with the groups into which morphologists have placed them. Apart from the widespread occurrence of specific component acids in certain plant families, there is observed a (probably gradual) simplification in fatty acid composition, commencing from the aquatic flora and proceeding in the direction of the fruit fats of the more highly developed land plants, similar to that which may be traced in the animal world. The facts to which attention is here directed illustrate that consistent and welldefined changes in biochemical as well as in biological conditions have accompanied evolutionary development in Nature.

\section{Flora of the Sahara Mountains}

\section{By Dr. J. Hutchinson}

$\mathrm{U}^{\mathrm{m}}$ NTIL a few years ago, the flora of the mountains in the Sahara desert was practically unknown. Modern means of transport, however, have rendered access to these remote masses comparatively easy, and their vegetation has been fairly well investigated during the last ten years or so.

There are two main ranges in the middle Sahara (Fig. 1), the Hoggar or Ahaggar Mountains, halfway between Tunis and Nigeria, and in a direct line between them, and the Tibesti Mountains, on the western border of the Libyan desert, about five hundred miles north-north-east of Lake Chad. Due mainly to the work of French explorers and Prof. René Maire, of the University of Algiers, botanical science is now furnished for the first time with lists of the species known from these two mountain masses, which, so far as their plantlife is concerned, are like islands in a wide ocean, the 'ocean' in this case being the barren sands of the Sahara Desert. To the north of this desert is the rich Mediterranean flora and that of the Great Atlas Mountains, and to the south the vast tropical flora of Central Africa.
Prof. Maire, in a paper entitled "Études sur la Flore et la Végétation du Sahara central" (Mém. Soc. Hist. Nat. Afr. Nord., No. $3 ;$ 1933), gives an account of the Hoggar Mountains flora, and last year there appeared his "Contribution à l'Étude de la Flore du Tibesti” (Mém. Acad. Sci. France, 62). The purpose of these notes is to compare the floras of the two mountain masses with each other and with the Mediterranean and tropical African floras to the north and south of them respectively.

Maire's contribution to our knowledge of the Central Sahara is an important one and is the result of a personal visit to the Hoggar Mountains in 1928 with a special mission organised by the governor of the territory. His account occupies 272 pages, and is illustrated by 36 photographs and 2 sketch maps. The coloured frontispiece of a lilac-flowered crucifer, Moricandia arvensis, DC., var. garamantum, Maire, shows how beautiful a flower-garden this arid region may become after rain, for it is the dominant plant of the 'acheb' on the Atakor plateau in the Hoggar Mountains. A white-flowered form occurs here and there. The 